\title{
논문 2013-08-41
}

\section{멀티홉 센서 네트워크에서 에너지 상황을 고려한 시스템 수명 최대화 알고리즘}

\section{(Energy-Aware System Lifetime Maximization Algorithm in Multi-Hop Sensor Network)}

\author{
김 태 림*, 김 범 수, 박 화 규 \\ (Tae-Rim Kim, Bum-Su Kim, Hwa-Kyu Park)
}

\begin{abstract}
This paper addresses the system lifetime maximization algorithm in multi-hop sensor network system. A multi-hop sensor network consists of many battery-driven sensor nodes that collaborate with each other to gather, process, and communicate information using wireless communications. As sensor-driven applications become increasingly integrated into our lives, we propose a energy-aware scheme where each sensor node transmits informative data with adaptive data rate to minimize system energy consumption. We show the optimal data rate to maximize the system lifetime in terms of remaining system energy. Furthermore, the proposed algorithm experimentally shows longer system lifetime in comparison with greedy algorithm.
\end{abstract}

Keywords : Multi-hop sensor network, Energy-performance optimization, Energy-constrained embedded system, System modeling, Network management

\section{I. 서 론}

센서 네트워크는 전쟁 지역의 일시적인 감시와 같은 군사용이나 안전 관리, 재난 관리와 같은 실생 활용으로 많은 사용이 가능하다[1]. 이러한 시스템 에서는 한 노드의 센서가 주변 관심 영역의 환경을 감시하여 데이터를 수집하며 이를 최종 목적지의 노드로 전송한다. 이러한 환경에서 사용하는 센서는 배터리를 활용하므로 큰 에너지를 필요로 하는 장 거리 통신은 지양한다. 또한 가혹한 외부 환경에 노 출되어 고장 날 확률이 큰 시스템에서는 주변의 노 드를 통해 멀티홉으로 최종 목적지 노드까지 정보 를 단거리 통신으로 전송하게 된다. 대부분의 센서 들은 일회용으로 배터리의 에너지를 모두 소모하여 방전하게 된다면 수명이 다해 더 이상 사용 가능하 지 못하게 된다. 따라서 무엇보다도 에너지의 사용 이 제한적인 수많은 노드로 구성된 멀티홉 센서 네 트워크 시스템에서는 적은 에너지를 사용하면서 가

* Corresponding Author (taerim.kim@lignex1.com) Received: 4 Sep. 2013, Revised: 24 Sep. 2013, Accepted: 2 Oct. 2013.

T.R. Kim, B.S. Kim, H.K. Park: LIG Nex1 (c) J. IEMEK 2013 Dec.: 8(6) 339-345

ISSN : $1975-5066$

http://dx.doi.org/10.14372/IEMEK.2013.8.6.339
능한 많은 정보를 전송하는 알고리즘을 설계하는 것이 중요하다.

배터리로 동작하는 멀티홉 센서 네트워크 시스 템에서는 에너지를 효율적으로 관리하기 위한 여러 가지 기법들이 소개되었다. 에너지 소모를 줄이기 위하여 통신 프로토콜 레이어에서의 제어도 중요하 지만 하드웨어 측면에서의 에너지 관리가 주로 제 안되어 왔다. 가장 대표적인 예로는 저전력 전기회 로 설계, 노드에 로드가 발생하지 않을 때의 파워 다운 모드 설계, 저에너지 사용으로의 효율적 통신 모듈레이션 기법 설계 등이 있다[2]. 또한 한 비트 를 전송하는데 소모되는 비용이 계산하는데 소모되 는 비용보다 크기 때문에 여러 센서들에서 수집한 정보를 하나의 클러스터 헤드에서 수집하여 데이터 를 전송하는 클러스터 개념의 센서 네트워크를 구 성하는 방법도 소개되었다[3]. 하나의 클러스터 헤 드에 의해 정보 집적과 전송이 이루어 질 경우 그 클러스터 헤드에서 에너지 소모가 극심해지기 때문 에 클러스터에서 헤드를 주기적으로 교체해줌으로 써 에너지를 비교적 균등하게 소모시키는 방법도 보여주었다[4]. 여기서는 클러스터 헤드의 배터리에 많은 에너지가 남아있더라도 주기적으로 클러스터 
헤드를 변경해줌으로써 주변의 노드에 가해지는 로 드를 줄여 시스템의 수명이 증가하는 것을 증명하 였다. 일반적으로 여러 센서들을 통하여 하나의 최 종 센서로 데이터가 이동하는 경우 최종 센서 주변 의 노드들에 큰 로드가 집중된다. 그 이외의 센서들 은 배터리의 에너지가 충분히 남아있음에도 불구하 고 전체 시스템의 네트워크는 분해되는 에너지 홀 현상이 일어날 수도 있는데 에너지를 효율적으로 분배하여 시스템의 수명이 끝날 때까지 $10 \%$ 미만 의 노드만 에너지가 남게 되는 기법을 이론적으로 기술하였다[5].

멀티홉 센서 네트워크와 관련하여 시스템의 수 명을 연장하기 위한 여러 가지 에너지 관리 논문이 소개되었다. 하지만 센서 노드들의 데이터 레이트를 적응적으로 변경함으로써 시스템의 총 에너지와 성 능의 균형을 유지하는 기법을 연구되지 않았다. 본 논문은 2장에서 멀티홉 센서 네트워크와 그 네트워 크를 이루고 있는 노드들의 에너지 모델과 파워 모 델을 제시한다. 3장은 2장에서 설계된 시스템 모델 을 가지고 시스템 에너지를 가능한 적게 사용하면 서 최대의 성능을 구현하기 위한 최적화 알고리즘 을 소개한다. 4장에서는 시뮬레이션을 통해 3장의 시스템 에너지를 고려한 성능 최적화 알고리즘을 분석적으로 검증해보고 마지막으로 5 장에서는 본 논문의 결론으로 끝을 맺는다.

\section{II . 시스템 모델링}

\section{1. 멀티홉 센서 네트워크}

멀티홉 센서 네트워크의 경우 노드의 물리적 전 송 거리의 한계 때문에 특정 데이터를 송신하기 위 하여 소스 노드에서 그 데이터를 최종적으로 수신 하는 데스티네이션 노드까지 다중 중간 릴레이 노 드를 통해서 데이터 이동이 이루어진다. 이때 중간 릴레이 노드에 의한 경로는 고정되어 있을 수도 있 지만 이럴 경우 특정 노드에 에너지가 집중적으로 소모되어 데스티네이션 노드까지의 네트워크가 분 해되는 현상이 발생하기 때문에 동적으로 경로의 변화를 설정해줄 필요가 있다. 소스 노드에서 데스 티네이션 노드까지 한 번에 직접 데이터를 송수신 하는 방법도 있지만 송신 거리에 따라 기하급수적 으로 에너지 소모가 증가하기 때문에 배터리를 이 용한 임베디드 시스템에서는 직접적으로 데이터를 송신하는 방법은 바람직하지 않다. 여기서 시스템이 란 센서 네트워크를 이루는 노드들의 총집합을 의

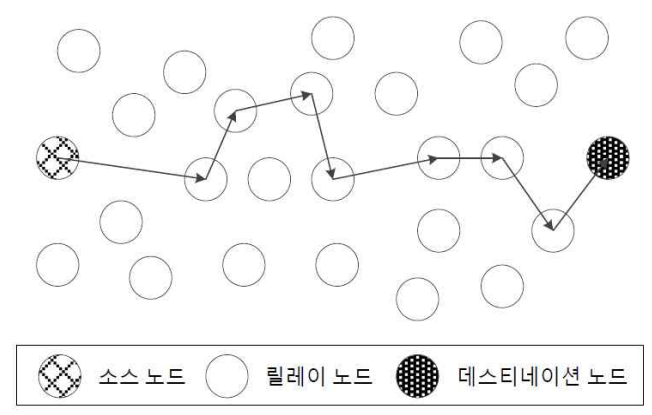

그림 1. 멀티홉 센서 네트워크

Fig. 1 Multi-hop sensor network

미한다.

단일 경로를 이용한 데이터 송수신에서 한 노드 의 에너지 고갈로 인한 경로 차단이 이루어지지만 멀티홉 센서 네트워크의 경우 다른 경로를 동적으 로 찾아 데스티네이션 노드로 데이터의 이동이 이 루어질 수 있기 때문에 임베디드 시스템에서 더욱 효과적인 통신 수단이 된다. 그림 1 은 이를 설명한 기본적인 멀티홉 센서 네트워크를 보여주고 있다.

\section{2. 노드 에너지 모델}

멀티홉 센서 네트워크를 이루는 3가지 노드는 데이터를 최초로 송신하는 소스 노드, 데이터를 최 종적으로 수신하는 데스티네이션 노드, 중간에서 소 스 노드의 데이터를 수신하여 데스티네이션 노드로 송신하여 주는 다중의 릴레이 노드로 이루어진다.

소스 노드의 경우 특정 확률을 가지고 데이터를 전송 범위 $L$ 내부에 있는 주변의 릴레이 노드로 전 송한다. 이때 소스 노드는 주변의 릴레이 노드 중에 최소의 에너지를 소모하는 릴레이 노드로 데이터를 전송하며 이를 계산하기 위한 부가적인 에너지 소 모가 있게 된다. 릴레이 노드의 경우 소스 노드 또 는 다른 릴레이 노드의 데이터를 수신하고 그 데이 터를 데스티네이션 노드 또는 다른 릴레이 노드로 송신하는데 에너지를 소모한다. 데스티네이션 노드 의 경우 릴레이 노드로부터 오는 데이터를 수신하 기 위해 에너지가 소모되며 이 데이터를 실제로 쓰 기 위하여 처리되는 데에도 추가적인 에너지가 필 요하게 된다. 뿐만 아니라 각각의 노드는 데이터를 송수신을 하고 있지 않은 정적인 상태에서도 주변 의 상황을 감지하고 내부 노드의 최소로 필요로 하 게 되는 에너지를 소모하게 된다. 릴레이 노드의 경 우 송수신되는 데이터를 가공하기 위한 추가적인 에너지 소모는 없다고 가정한다. 이에 따라 소스 노 
드 $(s)$, 릴레이 노드 $(r)$, 데스티네이션 노드 $(d)$ 에서 소모하는 에너지 $E_{s}, E_{r}, E_{d}$ 는 다음과 같이 정리할 수 있다.

$$
\begin{aligned}
& E_{s}=P_{t x(s)} T_{t x(s)}+P_{p(s)} T_{p(s)}+P_{s l p(s)} T_{s l p(s)} \\
& E_{r}=P_{r x(r)} T_{r x(r)}+P_{t x(r)} T_{t x(r)}+P_{s l p(r)} T_{s l p(r)} \\
& E_{d}=P_{r x(d)} T_{r x(d)}+P_{p(d)} T_{p(d)}+P_{s l p(d)} T_{s l p(d)}
\end{aligned}
$$

여기서 $P_{t x}, P_{r x}, P_{p}, P_{s l p}$ 과 $T_{t x}, T_{r x}, T_{p}, T_{s l p}$ 은 노드의 송신, 수신, 데이터 처리, 정적 상태에서 의 소모 전력과 상태 지속 시간을 나타낸다.

\section{1 송수신기 파워 모델}

송수신기의 에너지 소모 모델의 경우 대부분의 에너지 소모는 파워 앰프 $\left(P_{P A}\right)$ 와 $\mathrm{DA}$ 컨버터 $\left(P_{D A C}\right)$, 믹서 $\left(P_{m i x}\right)$, 필터 $\left(P_{f i l t}\right)$ 와 같은 기타 회로 $\left(P_{C C}\right)$ 에서 소모하는 것으로 알려져 있다[6].

$$
\begin{aligned}
P_{t x} & =P_{C C}+P_{P A} \\
& =P_{D A C}+P_{m i x}+P_{f i l t}+P_{P A}
\end{aligned}
$$

여기서 통신 채널이 $\sigma^{2}$ 의 분산을 가지는 가우시 안 코드북을 따른다는 가정 하에 통신 노드에서 형 성된 각 채널 $k$ 에서의 최대 데이터 레이트 $r_{k}$ 는 $p_{k}$ 의 전송 파워가 할당되었을 때 다음과 같이 정의된 다[7].

$$
r_{k}\left(p_{k}\right)=\log _{2}\left(1+\frac{p_{k}}{\sigma^{2}}\right)
$$

여기서 데이터 레이트는 응용계층에서의 데이터 전송률이다. 이에 따라서 특정 시간 $T_{c}$ 동안 $W_{c}$ 의 대역폭이 할당된 통신 노드에서 전체 채널의 개수 가 $K$ 개 형성되었다면 이때 송신되는 데이터 비트수 $B$ 와 이에 따라 송신기에서의 최종적인 데이터 레이 트 $R$ 은 다음과 같이 정의한다.

$$
\begin{aligned}
B & =T_{c} W_{c} \sum_{k=1}^{K} r_{k}\left(p_{k}\right) \\
& =T_{c} W_{c} \sum_{k=1}^{K} \log _{2}\left(1+\frac{p_{k}}{\sigma^{2}}\right)
\end{aligned}
$$

$$
\begin{aligned}
R & =\frac{B}{T_{t x}} \\
& =\frac{T_{c} W_{c}}{T_{t x}} \sum_{k=1}^{K} \log _{2}\left(1+\frac{p_{k}}{\sigma^{2}}\right)
\end{aligned}
$$

$P_{C C}$ 는 데이터 레이트에 비례하여 소모되며 이 에 따라 다음과 같이 정의한다.

$$
P_{C C}=\alpha R
$$

$\alpha$ 는 0 이상의 값을 갖는 비례상수이다. 또한 파 워 앰프에서 소모되는 파워 $P_{P A}$ 의 경우 다음과 같 이 정의할 수 있다[7].

$$
P_{P A}=\frac{\xi}{\eta} W_{c} \sum_{k=1}^{K} p_{k}
$$

$\xi$ 과 $\eta$ 는 각각 파워 앰프 출력의 백오프와 드레 인 효율도를 나타낸다. 따라서 (4), (8), (9)를 통해 서 최종적으로 송신기에서 소모되는 파워 모델은 다음과 같다.

$$
\begin{aligned}
P_{t x} & =P_{C C}+P_{P A} \\
& =\alpha R+\frac{\xi}{\eta} W_{c} \sum_{k=1}^{K} p_{k}
\end{aligned}
$$

수신기의 경우 송신기에서 많은 파워를 소모하 는 파워 앰프가 없지만 데이터를 전동하는 도중에 생기는 노이즈를 제거하기 위한 저잡음 증폭기(low noise amplifier)를 구성하고 있다. 저잡음 증폭기의 경우 거의 일정한 전류 $I_{r x}=P_{r x} /(\beta V)$ 에 의해 구동 되며 이때 $\beta$ 와 $V$ 는 각각 $\mathrm{DC}-\mathrm{DC}$ 컨버터의 전송 효율과 임베디드 시스템 배터리의 구동 전압이다. $\beta$ 는 $\mathrm{DC}-\mathrm{DC}$ 컨버터를 사용하지 않을 경우 1 로 고 정되며 사용할 경우 0 과 1 사이의 값을 가진다[8]. 일반적으로 $I_{r x}$ 의 경우 매우 작은 값을 가지며 $\mu\left(I_{r x}\right)=1-w I_{r x} \approx \mu_{\max }=1$ 로 $w$ 는 양의 값을 가진 다[9]. 따라서 수신기에서 소모되는 파워 모델은 다 음과 같다.

$$
P_{r x}=\beta V
$$

\section{2 데이터 처리 모듈 파워 모델}

본 논문에서는 데이터를 처리하기 모듈은 임베 
디드 프로세서만으로 제한한다. 임베디드 프로세서 의 경우 동적 상태에서의 파워와 정적 상태에서의 파워로 구분된다. 데이터 처리 모듈 파워 모델은 동 적 상태만을 고려하며 정적 상태는 " 2.3 정적 상태 파워 모델”에 포함한다. 일반적으로 $P_{p}$ 는 다음과 같이 정의된다[10].

$$
P_{p}=\frac{1}{2} C_{L} V^{2} f(R)
$$

여기서 $C_{L}$ 은 시스템에서의 로드 캐패시턴스이며 $f$ 는 스위칭 주파수로 데이터 레이트 $R$ 의 영향을 받 는다.

\section{3 정적 상태 파워 모델}

노드들이 데이터를 송수신하지 않고 있고 이에 따라 데이터를 처리하지 않는 정적 상태의 경우 최 소의 에너지를 소모하는 대기 상태로 전환된다. 상 황에 따른 데이터 레이트가 변화하지 않는 상태이 기 때문에 정적 상태의 경우 소모되는 파워는 노드 의 특성에 따라 변화하지 않고 고정적인 것으로 가 정한다.

$$
P_{s l p}=\gamma
$$

여기에는 임베디드 프로세서의 정적 상태 파워 도 포함한다.

\section{III. 에너지 상황을 고려한 성능 최적화}

노드는 배터리로 구동되고 배터리의 에너지가 고갈될 때까지 활성화되어 있기 때문에 시스템이 요구하는 특정 시간까지 시스템을 유지하기 위하여 자원의 레벨을 유지시킬 수 있는 최적의 구성을 찾 는 것이 중요하다. 각 노드에서의 에너지를 가장 많 이 소모하는 곳은 통신 회로와 데이터 처리 회로로 이러한 회로들의 최적의 구성을 결정함으로써 에너 지의 소모를 낮출 필요가 있다.

멀티홉 센서 네트워크 시스템을 성능적인 측면 에서 본다면 전체 시스템의 평균 데이터 레이트가 높아야 특정 시간 안에 가능한 많은 정보가 전달되 어야 할 것이다. 뿐만 아니라 배터리의 주기적인 충 전이 없는 상태라면 시스템 전체에서 소모되는 에 너지를 가능한 최소화해 시스템의 수명을 증가시켜 야 할 것이다. 이때 $i-1$ 번째 릴레이 노드에서 $i$ 번
째 릴레이로의 데이터 전송은 전체 시스템 노드가 가능한 균형 있게 에너지를 소모하게 한다. 그래서 소스 노드에서 데스티네이션 노드로의 경로가 다중 으로 형성될 수 있게 하기 위하여 전송 범위 $L$ 내 부에 있는 릴레이 노드 중에 최대의 에너지를 갖는 노드를 선택한다. 이를 수식화하면 다음과 같이 표 현할 수 있다.

$$
\begin{aligned}
& \text { minimize } \frac{E_{\text {sys }} /\left\|E_{\text {sys }}\right\|}{R_{\text {sys }} /\left\|R_{\text {sys }}\right\|} \\
& \text { s.t. } E_{r}^{i}=\max \left(C_{r}^{1^{*}}-C_{r}^{1}, \cdots, C_{r}^{j^{*}}-C_{r}^{j}\right)
\end{aligned}
$$

여기서 $j$ 는 $i-1$ 번째 릴레이에서 전송 범위 $L$ 내부에 있는 주변의 릴레이 노드들을 나타낸다. $C_{r}^{j^{*}}$ 과 $C_{r}^{j}$ 는 각각 데이터 이동 경로의 릴레이 노드 $j$ 에 서 현재 남아있는 에너지와 데이터의 송수신 및 처 리에 소모되는 에너지이다. $M$ 번의 홉을 거치는 멀 티홉 센서 네트워크에서 소스 노드로부터 $M-1$ 번 의 릴레이 노드를 지나 데스티네이션 노드까지 데 이터를 송수신할 때 전체 시스템에서 소모되는 에 너지 $E_{s y s}$ 는 다음과 같다.

$$
E_{\text {sys }}=E_{s}+\sum_{i=1}^{M-1} E_{r}^{i}+E_{d}
$$

또한 전체 시스템에서의 평균 데이터 레이트 $R_{s y s}$ 는 다음과 같다.

$$
R_{s y s}=\frac{R_{s} T_{t x(s)}+\sum_{i=1}^{M-1} R_{r}^{i} T_{t x(r)}^{i}}{T_{t x(s)}+\sum_{i=1}^{M-1} T_{t x(r)}^{i}}
$$

$R_{s}$ 과 $R_{r}^{i}$ 는 소스 노드와 데이터 이동 경로의 $i$ 번 째 릴레이 노드에서의 데이터 레이트를 의미한다. $\left\|E_{s y s}\right\|$ 와 $\left\|R_{s y s}\right\|$ 는 $E_{\text {sys }}$ 와 $R_{\text {sys }}$ 에 대한 정규화 상수이다. 여기서 $E_{s y s}$ 와 $R_{s y s}$ 의 상관관계를 찾아볼 수 있다. 소스 노드에서 많은 정보를 보내기 위해 고속의 데이터 레이트로 정보를 전송할 경우 멀티 홉 센서 네트워크 시스템의 성능적인 측면에서는 향상을 보이게 된다. 하지만 배터리의 주기적인 교 체가 없는 임베디드 시스템의 노드라면 이러한 고 속의 전송 방식은 시스템의 수명을 단축시키는 결 과를 초래하게 될 것이다. 이렇듯 시스템 에너지와 


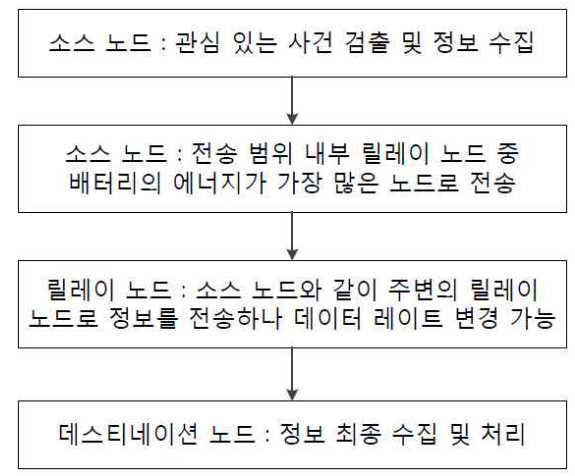

그림 2. 제한된 에너지 환경 속에서 정보 전송 방법

Fig. 2 Information transmission scheme in energy-constrained environment

평균 데이터 레이트 사이에는 트레이드오프의 관계 를 보이고 있으며 시스템의 수명을 최대화할 수 있 는 최적의 데이터 레이트가 존재하는 것을 알 수 있다. 그림 2 는 소스 노드에서 릴레이 노드를 거쳐 데스티네이션 노드까지 데이터를 전송할 때 시스템 의 수명을 최대화하기 위한 방법을 간략히 보여주 고 있다.

\section{IV. 시뮬레이션 및 분석}

\section{1. 설정}

센서 노드들은 $1000 \mathrm{~m} \times 1000 \mathrm{~m}$ 의 2 차 공간에 무 작위로 배치되었으며 각 센서 노드의 전송 범위 $L$ 은 최대 $75 \mathrm{~m}$ 로 제한한다. 또한 초기 배터리 용량은 사용으로 쓰이는 일반 $\mathrm{AA}$ 알카라인 배터리인 $3600 \mathrm{mWh}$ 이고 4 개의 배터리를 병렬로 연결하여 사 용한다. 송수신 후 데이터를 가공하기 위하여 처리 하는 로직은 임베디드 프로세서로 한정하며 본 논 문은 ARM7 프로세서로 이때 소모하는 파워와 동작 시간은 파워 모델과 SimpleScalar를 이용하여 계산 하였다. 소스 노드 주변에서 관심 있는 사건이 일어 날 확률은 0.25 로 베르누이 분포를 갖는다고 가정 하며 각 노드의 송신기에서 전송하는 데이터 레이 트 $W_{c}$ 는 최대 $50 \mathrm{kbps}$ 로 제한하며 각 노드당 통신 을 위해 생성되는 채널의 개수 $K$ 는 1 개이다.

\section{2. 결과 및 고찰}

그림 3은 시스템 전체 노드의 배터리에 남아있 는 에너지가 각각 $100 \%, 75 \%, 50 \%$ 일 때 데이터

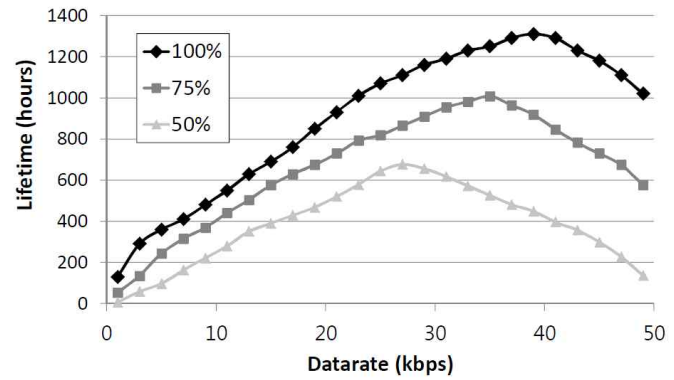

그림 3. 시스템 전체에 남아있는 에너지에 따른 데이터 레이트와 시스템 수명의 상관관계

Fig. 3 Relationship between data rate and system lifetime for remaining system energy

레이트를 고정해놓고 송수신을 할 경우 시스템의 수명을 보여주고 있다. 여기서 시스템의 수명은 소 스 노드로부터 데스티네이션 노드까지의 경로가 주 변의 릴레이 노드들의 배터리 고갈로 사라질 때까 지의 시간을 의미한다. 그림에서 볼 수 있듯이 시스 템의 남아있는 에너지에 따라 시스템의 수명을 최 대화할 수 있는 데이터 레이트가 변화하는 것을 확 인할 수 있겠다. $100 \%$ 의 경우 $39 \mathrm{kbps}$ 의 속도로 송 수신할 때 1310 시간의 시스템 수명이 측정되었으며 $75 \%$ 의 경우 $35 \mathrm{kbps}$ 에서 1008 시간, $50 \%$ 의 경우 $27 \mathrm{kbps}$ 에서 676 시간이 측정되었다. 이는 시스템의 에너지가 많이 남아있을 경우 비교적 고속으로 데 이터를 송수신함으로써 시스템의 성능을 높이려는 경향이 있는 것이다. 하지만 점점 에너지가 소모됨 에 따라 시스템의 에너지는 줄어들고 데이터 레이 트를 감소시켜 시스템의 성능을 줄이지만 시스템의 수명을 증가시키려는 경향이 있음을 보여주고 있다. 즉 데이터 레이트와 시스템 수명 사이에는 트레이 드 오프(trade-off)가 존재하여 시스템의 수명을 최 대화하는 데이터 레이트가 있으며 최적의 레이트는 시스템에 남아있는 전체 에너지에 따라 다르다. 따 라서 외부로부터 추가적이 에너지 공급이 없는 멀 티홉 센서 네트워크에서는 소스 노드에서 릴레이 노드를 걸쳐 데스티네이션 노드로 전송되는 데이터 를 최대화하면서 동시에 시스템 수명도 최대화하기 위해서 시스템에 남아있는 전체 에너지에 따라 적 응적으로 데이터 레이트를 변경할 필요가 있겠다.

그림 4 는 본 논문에서 제안한 알고리즘과 그리 디 알고리즘 사용에 따른 시스템 수명을 보여주고 있다. 여기서 사용한 그리디 알고리즘은 데이터를 수신한 릴레이 노드가 주변의 후보 릴레이 노드로 데이터를 송신하기 위하여 최적의 릴레이 노드로 


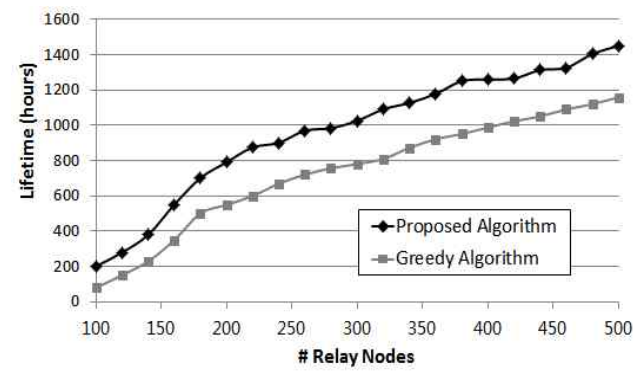

그림 4. 제안된 알고리즘과 그리디 알고리즘에 따른 릴레이 노드 수와 시스템 수명의 상관관계

Fig. 4 Relationship between the number of relay nodes and system lifetime for proposed algorithm and greedy algorithm

최대의 에너지를 가진 노드를 선택한다. 즉 본 논문 에서 제안된 알고리즘과 다르게 그리디 알고리즘은 에너지만을 고려하게 되며 데이터 레이트의 변경은 고려하지 않는다. 그림에서 볼 수 있듯이 그리디 알 고리즘에 비하여 제안한 알고리즘이 평균 200시간 정도 시스템 수명이 길어지는 것을 볼 수 있다. 이 는 후보 릴레이 노드들 중에서 데이터 레이트에 따 른 남게 될 릴레이 노드의 에너지를 고려함으로써 시스템의 에너지를 비교적 균등하게 소모한다는 것 을 의미한다. 또한 릴레이 노드의 수가 증가함에 두 알고리즘 사이의 시스템 수명의 차이도 증가하는 것을 볼 수 있다. 릴레이 노드의 수가 적을 때는 한 릴레이 노드에서 주변으로 전송할 수 있는 릴레이 노드의 수가 적어 그리디 알고리즘과 제안된 알고 리즘과 상관없이 동일한 릴레이 노드로 전송되는 확률이 크지만 많은 수의 릴레이 노드가 배치될수 록 주변의 이웃 릴레이 노드의 수도 많아져 두 알 고리즘의 차이로 전송되는 릴레이 노드가 다르게 될 확률이 증가하게 되는 것이다.

\section{V. 결 론}

본 논문에서는 멀티홉 센서 네트워크에서 시스 템 에너지를 적게 사용하면서 최대의 성능을 구현 하기 위한 최적화 알고리즘 소개하였으며 여기서 노드들에서 소모되는 에너지를 계산하기 위하여 에 너지 소모 모델도 설계해 보았다. 제안한 알고리즘 은 소스 노드에서 데스티네이션 노드로 전송하는 사이에 있는 릴레이 노드들을 결정하기 위하여 릴 레이 노드들의 에너지를 고려할 때 남아있는 에너 지뿐만 아니라 데이터 송수신시 소모되는 에너지를
데이터 레이트와 관계하여 추가적으로 고려해주었 다. 이를 통해서 시스템의 수명을 최대화하는 최적 의 데이터 레이트는 남아있는 에너지에 따라 변화 한다는 것을 실험적으로 확인해보았다.

이번 논문에서 제안한 알고리즘은 디자인 타임 에서 최적의 데이터 레이트를 찾는 기법으로 실제 배터리를 사용하는 시스템에서는 계산의 복잡성으 로 인한 극심한 에너지 소모로 적용하기는 힘들다. 따라서 추후에는 런 타임에서 실시간 환경에 적응 적으로 적용할 수 있는 알고리즘 연구가 기대된다.

\section{References}

[1] M. Younis, M. Youssef, K. Arisha, "Energy-aware routing in cluster-based sensor networks," Proceedings of the 10th IEEE/ACM International Symposium on Modeling, Analysis and Simulation of Computer and Telecommunication Systems, 2002.

[2] P.J.M. Havinga, G.J.M. Smit, "Design techniques for low power systems," Journal of Systems Architecture, Vol. 46, No. 1, pp.1-21, 2000.

[3] S. Bandyopadhyay, E. Coyle, "An energy efficient hierarchical clustering algorithm for wireless sensor networks," Proceedings of INFOCOM, Vol. 3, pp.1713 - 23, 2003.

[4] V.P. Mhatre, C. Rosenberg, D. Kofman, R. Mazumdar, N. Shroff, "A minimum cost heterogeneous sensor network with a lifetime constraint," IEEE Transactions on Mobile Computing, Vol. 4, No. 1, pp.4-15, 2005.

[5] X. Wu, G. Chen, S.K. Das. "Avoiding energy holes in wireless sensor networks with nonuniform node distribution," IEEE Transactions on Parallel and Distributed Systems, Vol. 19, No. 5, pp.710-720, 2008.

[6] S. Cui, A.J. Goldsmith, "Energy-constrained modulation optimization," IEEE Transactions on Wireless Communications, Vol. 4, No. 5, pp.2349-2369, 2005.

[7] C. Isheden, Z. Chong, E. Jorswieck, G. Fettweis, "Framework for link-level energy efficiency optimization with informed 
transmitter," IEEE Transactions Wireless Communications, Vol. 11, No. 8, pp.2946-2957, 2012.

[8] D. Duan, F. Qu, L. Yang, A. Swami, J.C. Principe, "Modulation selection from a battery power efficiency perspective," IEEE Transactions on Communications, Vol. 58, No. 7, pp.1907-1911, 2010.

[9] Q. Tang, L. Yang, G.B. Giannakis, T. Qin, "Battery power efficiency of PPM and FSK in wireless sensor networks," IEEE Trans. Communications, Vol. 6, No. 4, pp.1308-1319, 2007.

[10] A. Varma, B. Jacob, E. Debes, I. Kozintsev, P. Klein. "Accurate and fast system-level power modeling: An xscale-based case study," ACM Transactions in Embedded Computing Systems, Vol. 6, No. 4, 2007.

\section{저 자 소 개}

\section{김 래 림}

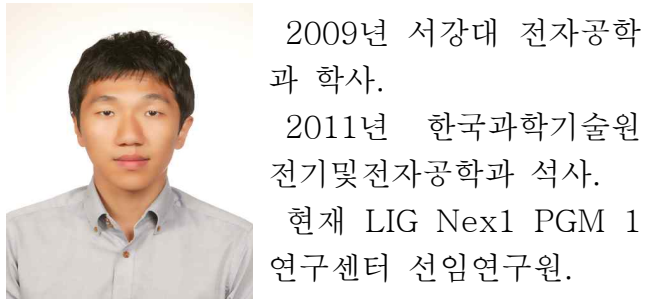

관심분야: 임베디드 시스템, 시스템 엔지니어링.

Email: taerim.kim@lignex1.com

김 범 수

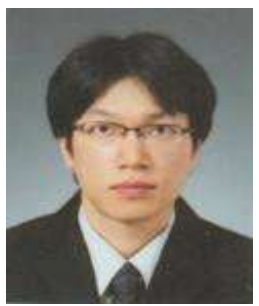

2005년 광운대 전자재료 공학과 학사.

현재 LIG Nex1 PGM 1 연구센터 선임연구원.

관심분야: 임베디드 시스 템, 시스템 엔지니어링.

Email: genkbs71@lignex1.com

\section{박 화 규}

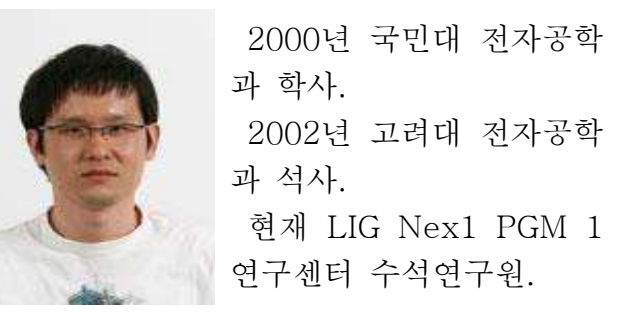

관심분야 임베디드 소프트웨어, 시스템 엔지니어링. Email: hwakyupark@lignex1.com 